\title{
Single-visit Apexification using Calcium Phosphate Cement
}

\author{
${ }^{1} \mathrm{CS}$ Deviprasad, ${ }^{2} \mathrm{G}$ Praveena, ${ }^{3}$ Manoj C Kuriakose, ${ }^{4}$ Neethu Rajeev, ${ }^{5}$ Athira A Hari
}

\begin{abstract}
An immature tooth with pulpal necrosis and periapical pathology imposes a great difficulty to the endodontists. Endodontic treatment options for such teeth consist of conventional apexification procedure with and without apical barriers and revascularization. Calcium phosphate is a calcium silicate-based cement that exhibits physical and chemical properties similar to those described for certain Portland cement derivatives. This article demonstrates the use of calcium phosphates as an apical matrix barrier in root end apexification procedure. This case report presents apexification and follow-up of a case with the use of calcium phosphate as an apical barrier matrix.
\end{abstract}

Keywords: Apexification, Apical barrier, Calcium phosphate cement.

Howto cite this article:DeviprasadCS, PraveenaG, KuriakoseMC, Rajeev N, Hari AA. Single-visit Apexification using Calcium Phosphate Cement. Cons Dent Endod J 2016;1(2):46-49.

\section{Source of support: Nil}

Conflict of interest: None

\section{INTRODUCTION}

The management of a nonvital tooth with open apex involves the induction of a natural or artificial apical barrier that can act as a stop for the obturating material. ${ }^{1}$ Traditionally, a thick mix of calcium hydroxide is used to initiate hard tissue formation. But there are certain disadvantages associated with this conventional method. The average time taken for apexification to complete using calcium hydroxide is 6 to 24 months, and this prolonged time period can promote bacterial recontamination. Previous studies have described the disadvantages of calcium hydroxide apexification, such as failure to control infection, recurrence of infection, and cervical fracture. ${ }^{2,3}$ Thus, although the apexification technique with calcium hydroxide has enjoyed considerable success, the many disadvantages of this protracted treatment have justified

\footnotetext{
1,4,5 Postgraduate Student (Final Year), ${ }^{2,3}$ Professor

${ }^{1-5}$ Department of Conservative Dentistry and Endodontics, Azeezia College of Dental Sciences and Research, Kollam, Kerala, India

Corresponding Author: CS Deviprasad, Postgraduate Student (Final Year), Department of Conservative Dentistry and Endodontics Azeezia College of Dental Sciences and Research, Kollam, Kerala India, Phone: +919605194714, e-mail: deviprasadcs@gmail.com
}

a search for alternatives, such as artificial apical barrier techniques, with their potential for more rapid treatment; and regeneration techniques, with their potential for continued tooth development.

Artificial apical barrier technique consists of a barrier material which is packed into the apical portion of the root canal against which the obturating material can be condensed. Clinicians have tried several materials to form apical barrier in the past. These include calcium hydroxide powder, calcium hydroxide mixed with different vehicles, collagen, tricalcium phosphate, osteogenic protein, bone growth factor, and oxidized cellulose.

Among the various materials used as artificial apical barrier, mineral trioxide aggregate (MTA) is currently considered as one of the most promising material. ${ }^{4} \mathrm{Min}-$ eral trioxide aggregate has some drawbacks as well. It has shown high solubility, demonstrating $24 \%$ loss after 78 days of storage in water., ${ }^{5,6}$ A significant downside to MTA is the prolonged setting time of approximately 2 hours and 45 minutes as well as the difficult handling characteristics. ${ }^{7}$ Calcium phosphate cement (CPC) has received a lot of research attention in recent years due to their chemical similarity to bones and teeth. They are useful biomedical materials owing to their excellent biocompatibility and the nontoxicity of their chemical components. The CPC powder consisted of tetracalcium phosphate (TTCP), $\mathrm{Ca}_{4}\left(\mathrm{PO}_{4}\right)_{2} \mathrm{O}$, and dicalcium phosphate anhydrous (DCPA), $\mathrm{CaHPO}_{4}$; when mixed with water at a powder:liquid ratio of 4:1, the paste hardened in about 30 minutes and formed hydroxyapatite. Calcium phosphate cement showed osteoconductivity, and was able to be resorbed and replaced by new bone. ${ }^{8}$

This case report highlights the nonsurgical management of teeth with immature apex and periapical radiolucency. Calcium phosphate cement is used as a matrix to promote periapical healing.

\section{CASE REPORT}

A 17-year-old male patient reported to the Department of Conservative Dentistry and Endodontics with a complaint of mild tooth discoloration in upper anterior region (Fig. 1). He had a history of trauma to the permanent maxillary left central incisor (21) 7 years back. He met with a road traffic accident the day before and 11 and 12 got avulsed. He sought immediate medical attention and came to the 


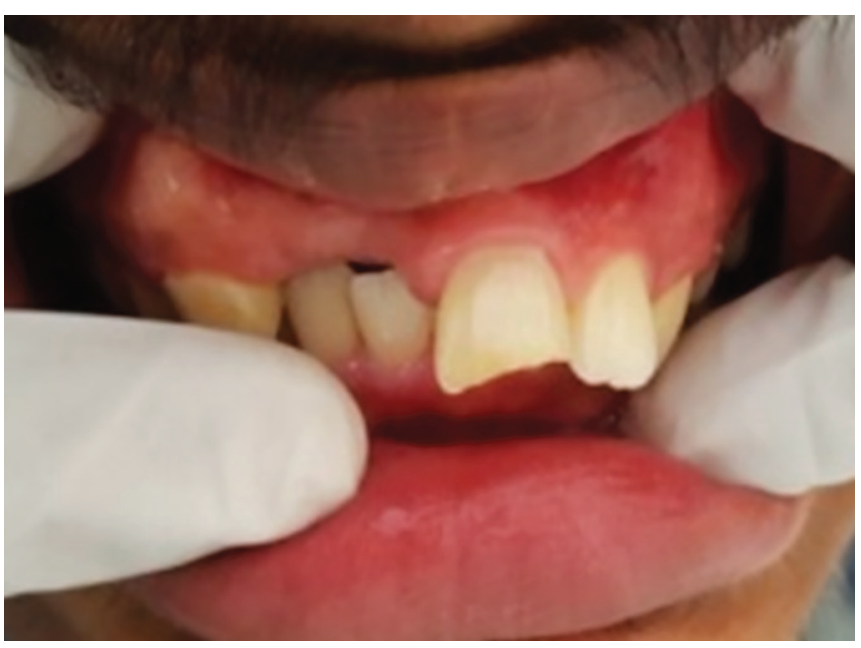

Fig. 1: Preoperative photograph

dental college the very next day. Intraoral examination revealed slight yellowish discoloration and proclination of 21. The tooth had Ellis class III fracture. Tooth was asymptomatic, nontender, and mobility within physiologic limits. The pulp vitality tests showed no response. His 11,12 was found to be missing. Medical history was noncontributory. Radiographic examination revealed a wide root canal with an open apex and periapical radiolucency in relation to 21 (Fig. 2). Based on the history and the radiographic findings, a diagnosis of chronic apical periodontitis with open apex of 21 was made.

After explaining to the patient it was decided to start the apexification procedure for apical closure and to promote periapical healing of 21. Treatment was started after obtaining informed consent and access was made in relation to 21 . After working length determination, cleaning and shaping was done up to 100 size K-file. 3\% Sodium hypochlorite and saline were used as irrigants. Calcium hydroxide powder was mixed with saline and was placed in the root canal for 2 weeks. In the next appointment, root canal was dried and CPC (Sree Chitra Institute of Biomedical Research) was mixed with the supplied distilled water to make a thick paste and was placed at the apex for a thickness of $3 \mathrm{~mm}$ using pluggers.

Apical barrier placement was done with calcium phosphate cement and master cone selection by rolled cone technique. Since the tooth had a wide root canal, the remaining part was filled with gutta-percha using custom-made cone with AH Plus as sealer (Fig. 3). Access cavity was sealed with glass ionomer cement and appointment was given for follow-up.

\section{DISCUSSION}

Apexification is defined as "a method to induce a calcified barrier in a root with an open apex or the continued apical development of an incomplete root in teeth with necrotic

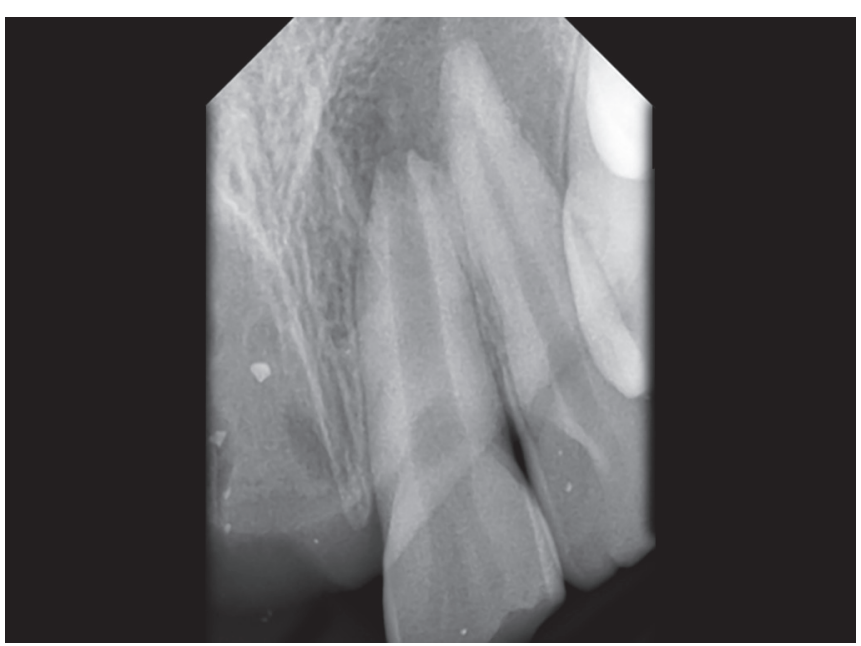

Fig. 2: Preoperative radiograph

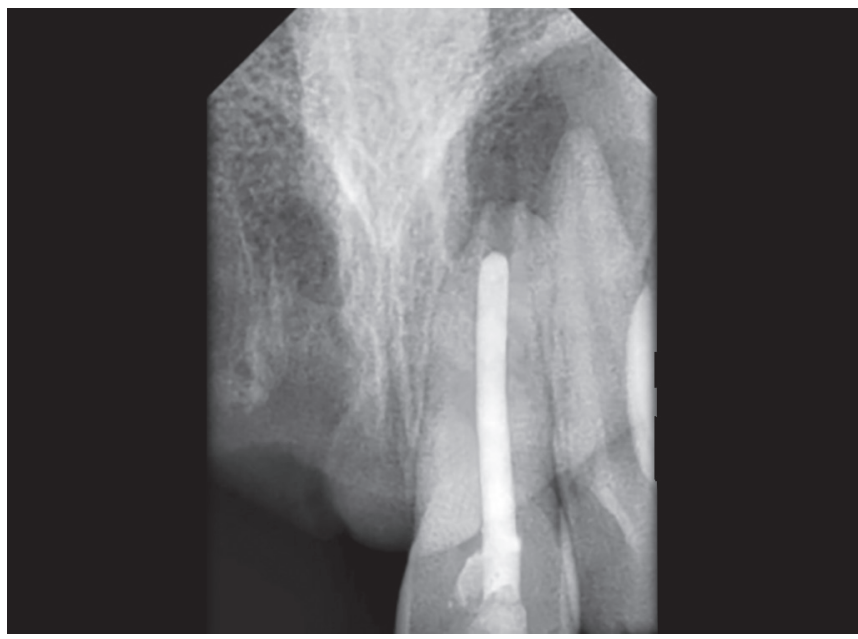

Fig. 3: Radiograph showing immediate obturation after placement of $3 \mathrm{~mm}$ apical barrier of calcium phosphate

pulp". ${ }^{9}$ The goal of this treatment is to obtain an apical barrier to prevent the passage of toxins and bacteria into periapical tissues from the root canal. Technically, this barrier is necessary to allow compaction of root filling material. Traditionally, calcium hydroxide has been used for apexification. Despite higher success rate of apical barrier formation using calcium hydroxide, longterm follow-up is essential. A suitable biocompatible material reduces leakage in the sealing material and allows favorable response of the periodontal tissues for periapical healing and apexification. Since the barrier formed by calcium hydroxide is porous and brittle, we cannot rely on its barrier formation.

Bioceramic materials, such as MTA, Biodentine, calcium-enriched mixture, and CPC are tried for apexification. The first self-hardening CPCs were developed in late 1980s. Calcium phosphate cement is a mixture of two calcium phosphate compounds, one acidic and another basic. The acidic component is dicalcium phosphate dehydrate and basic is tetra calcium phosphate. When mixed 
with aqueous solution it sets into a hard mass, the end product being hydroxyapatite. This cement is applied as a paste and shaped during placement. Calcium phosphate cement has good handling characteristics when compared to MTA. Calcium phosphate cement is inexpensive and also has antibacterial property, which is attributed to its high $\mathrm{pH}$ in the order of 12 . The setting time was found to be approximately 20 minutes..$^{10}$ The $\mathrm{X}$-ray diffraction spectrum of the cement showed similarity to that of bone mineral (hydroxyapatite particles). The compressive strength was observed to be 11-12 MPa, which is in the range of trabecular bone. ${ }^{11}$

Surgical approach was not used here as the root formation was not complete. Surgical procedure can damage the thin fragile root tip and it may also result in variation in crown root ratio. In this case, calcium hydroxide was used as an intracanal medicament for 2 weeks. It has got antiseptic action due to high $\mathrm{pH}$. High alkaline $\mathrm{pH}$ neutralizes the acidic $\mathrm{pH}$ created by the residual chronic inflamed tissue. It creates a favorable environment for healing. The tooth had a wide root canal; a custom-made gutta-percha cone was used for obturation.

Calcium phosphate cement is used for replacement of bone lost volume in craniofacial surgeries. There are several dental applications for CPC, including root canal sealer, furcation repair, and base applications. Calcium phosphate cement containing dental composites were also developed. Recently, CPC was also combined with a biopolymer chitosan to yield a strong and nonrigid hydroxyapatite composite for periodontal bone repair. ${ }^{12}$ Oqata et $\mathrm{al}^{13}$ investigated the mineralizing ability of a premixed CPC compared to MTA and zinc oxide eugenol cement (SuperEBA). Using a cell culture insert method premixed-CPC and MTA indicated significantly higher cell proliferation, alkaline phosphatase activity, mineralized nodule formation, and calcium content in nodules than those of SuperEBA. Therefore it was concluded that premixed-CPC has the same mineralizing ability as MTA. In a more recent study, the effect of CPC on growth and odontoblastic differentiation in human dental pulp cells was investigated. Odontoblastic differentiation was evidenced by the formation of mineralized nodules and induction of alkaline phosphatase activity. ${ }^{14}$

The cement powder was mixed with the distilled water supplied by the manufacturer to make a thick paste. The mix was rolled using the spatula since it had a better consistency compared to MTA and was placed in the root canal using pluggers to a thickness of $3 \mathrm{~mm}$. He was recalled after 3 months and radiograph showed reduction in size of the periapical lesion with signs of apical healing (Fig. 4). The tooth was asymptomatic, nontender, and

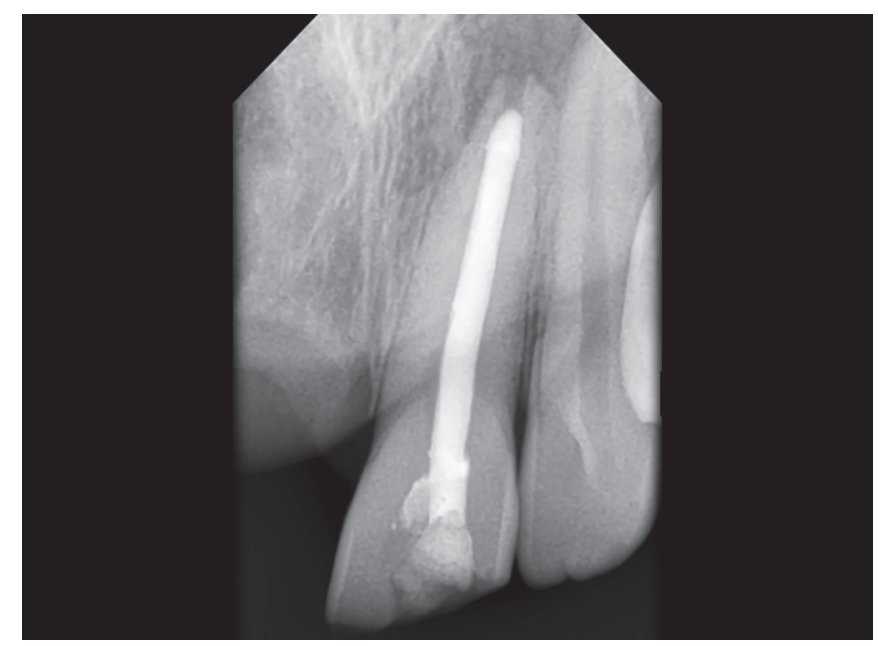

Fig. 4: Three months postoperative view

periapical area appeared normal. He was advised to come after 3 months for further evaluation and for crowning.

\section{CONCLUSION}

Nonsurgical management of open apex involves thorough debridement of root canal and placement of bioceramic material at the apex. Calcium hydroxide has been widely used for apexification. But now various other materials like MTA, Biodentine, calcium sulphate and CPC are used to promote periapical healing and apical closure. Calcium phosphate is a bioceramic material commonly used by orthopedicians for replacing bony defects. Calcium phosphate cement has got better handling properties and is cheaper compared to MTA, but it is inferior in radiopacity with only clinical verification possible. Calcium phosphate can be considered as a predictable treatment option and may be an alternative to MTA for apexification. However, further clinical follow-up has to be done to find out the prognosis and extend of apical barrier formation.

\section{REFERENCES}

1. Andreasen JO, Flores MT. Injuries to developing teeth. In: Andreasen JO, Andreasen FM, Andersson L, editors. Textbook and color atlas of traumatic injuries to the teeth. 4 th ed. Copenhagen: Munksgaard; 2007. p. 542-576.

2. Leonardo MR, Silva LA, Leonardo Rde T, Utrilla LS, Assed S. Histological evaluation of therapy using a calcium hydroxide dressing for teeth with incompletely formed apices and periapical lesions. J Endod 1993Jul;19(7):348-352.

3. Felippe MC, Felippe WT, Marques MM, Antoniazzi JH. The effect of renewal of calcium hydroxide paste on the apexification and periapical healing of teeth with incomplete root formation. Int Endod J 2005Jul;38(7):436-442.

4. Parirokh M, Torabinejad M. Mineral trioxide aggregate: a comprehensive literature review - Part I: chemical physical and antibacterial properties. J Endod 2010 Jan;36(1):16-27.

5. Fridland M, Rosado R. Mineral Trioxide aggregate (MTA) solubility and porosity with different water-to-powder ratios. J Endod 2003 Dec;29(12):814-817. 
6. Fridland M, Rosado R. MTA solubility: a long-term study. J Endod 2005 May;31(5):376-379.

7. Islam I, Chng HK, Yap AU. Comparison of the physical and mechanical properties of MTA and Portland cement. J Endod 2006 Mar;32(3):193-197.

8. Ishikawa K, Asaoka K. Estimation of ideal mechanical strength and critical porosity of calcium phosphate cement. J Biomed Mater Res 1995 Dec;29(12):1537-1543.

9. American Association of Endodontists. Glossary of endodontic terms. 7th ed. Chicago (IL): American Association of Endodontist; 2003.

10. Brown WE, Chow LC. A new calcium phosphate setting cement. J Dent Res 1983;62(Special issue):672.
11. Fukase Y, Eanes ED, Takagi S, Chow LC, Brown WE. Setting reactions and compressive strengths of calcium phosphate cements. J Dent Res 1990 Dec;69(12):1852-1856.

12. Takagi S, Chow LC, Hirayama S, Eichmiller FC. Properties of novel resorbable chitosan-calcium phosphate composites. Dent Mater 2003;19:797-804.

13. OqataH,Hayashi M,TsudaH,Suzuki N,MaenoM,SugawaraA, Ogiso B. Effects of a calcium phosphate cement on mineralized nodule formation compared with endodontic cements. Dent Mater J 2012 Feb3;31(1):92-97.

14. Kyung LS, Lee SK, Lee SI, Park JH, Jang JH, Kim HW, Kim EC. Effect of calcium phosphate cements on growth and odontoblastic differentiation in human dental pulp cells. J Endod 2010 Sep;36(9):1537-1542. 